J. Clin. Chem. Clin. Biochem.

Vol. 27, 1989, pp. 205-209

(C) 1989 Walter de Gruyter \& Co.

Berlin · New York

\title{
Urinary Oestriol-16-Glucuronide Determined by "On-Line" Liquid Chromatography
}

\author{
By U. Tiel, P. Heilmann
}

Städtisches Krankenhaus Berlin-Spandau, Abteilung für Laboratoriumsmedizin, Berlin, F.R.G.

\section{R. Rejaibi}

Institut für Klinische Chemie und Biochemie, Universitätsklinikum Rudolf Virchow, Standort Charlottenburg, Berlin, F.R.G. and

\section{Schöneshöfer}

Städtisches Krankenhaus Berlin-Spandau, Abteilung für Laboratoriumsmedizin, Berlin, F.R.G.

(Received August 18/November 29, 1988)

Summary: A fully automated method for the specific assessment of oestriol-16-glucuronide in urine is described. "On-line" sample preparation, including enrichment, pre-purification, focusing and injection, is combined with automated high-performance liquid chromatographic separation and fluorimetric quantification.

Losses of oestriol-16-glucuronide throughout the total procedure are negligible. Thus, external calibration is feasible for quantification. Coefficients of variation are $4.44 \%(n=12)$ for intra- and $7.85 \%(n=9)$ for interassay variability. Assay sensitivity is $430 \mathrm{nmol} / \mathrm{l}$.

The excretion rates of oestriol-16-glucuronide relative to creatinine were estimated in 85 pregnancy urines. These oestriol-16-glucuronide estimates correlated well with those of total urinary oestriol, determined by high-performance liquid chromatography after acid hydrolysis $(r=0.957)$. The reference ranges of oestriol16-glucuronide for the different weeks of gestation were evaluated.

Unlike the determination of total oestriol, the present method does not need an hydrolysis step. The method is therefore well suited for the biochemical monitoring of fețal well-being under emergency conditions.

\section{Introduction}

In pregnancy, oestriol is produced in the placenta from maternal and fetal precursors (particulary cholesterol). Thus, the excretion of total urinary oestriol in pregnancy urine is commonly used for the biochemical monitoring of the function of the maternal/ fetal unit. Since, in the maternal circulation, oestriol is almost completely in the form of various conjugates with glucuronic and/or sulphuric acid, it must be liberated from these renally excreted derivatives by hydrolysis before quantification.
In the routine laboratory, the total oestriol, released by hydrolysis, is finally estimated by radioimmunoassay methods $(1,2)$ or by more specific liquid chromatographic techniques with ultraviolet or fluorimetric detection $(3-6)$.

A disadvantage of all these methods for the estimation of total urinary oestriol is the necessity for the time consuming and often poorly reproducible hydrolysis of the oestriol conjugates.

An advantageous alternative, requiring no hydrolysis, is the direct estimation of oestriol-16-glucuronide, 
which represents about $70 \%$ of total oestriol-conjugates.

Recently, a liquid chromatographic method for the estimation of oestriol-16-glucuronide in native urine was described (5). In our hands, this direct technique of oestriol-16-glucuronide estimation, however, was subject to significant analytical interferences in certain urine samples. For the specific, liquid chromatographic estimation, therefore, time consuming sample clean-up steps are still mandatory (4).

Here, we describe a fully automated liquid-chromatographic method for the specific determination of oestriol-16-glucuronide, which includes automatic sample clean-up and fluorimetric detection.

We compared estimates of oestriol-16-glucuronide determined by this method with those of total urinary oestriol determined by a chromatographic technique using ultraviolet absorption for detection.

\section{Materials}

\section{Chemicals}

Oestriol and oestriol-16-glucuronide were obtained from Sigma, Munich, F.R.G.

Other reagents were of analytical grade and purchased from Merck Ltd., Darmstadt, F. R. G.

\section{Solvents}

For sample clean-up and chromatography, we used the following solvents:

methanol, acetonitrile, deionized water, $20 \mathrm{mmol} / 1 \mathrm{LiOH}, 20$ $\mathrm{mmol} / \mathrm{l}$ tris(hydroxymethyl)methylamine acetate, $50 \mathrm{mmol} / \mathrm{l}$ trifluoroacetic acid, $20 \mathrm{mmol} / 1$ phosphoric acid and $20 \mathrm{mmol} / \mathrm{l}$ citric acid.

All solvents were degassed with helium, and freshly purified "on-line": the water and all acid solutions by passage through Sep Pak $\mathrm{C}_{18}$ cartridges (Waters Assoc., Königstein/Taunus, F. R. G.); LiOH by passage through cartridges packed with 10 $\mu \mathrm{m}$ PRP-I particles (Hamilton, Reno, NV, USA); methanol and acetonitrile by passage through cartridges packed with $10 \mu \mathrm{m}$ alumina particles (Machery-Nagel, Düren, F. R. G.).

Organic and aqueous mixtures of solvents were prepared "online" by the corresponding pumps of the automatic sample clean-up device.

\section{Instrumentation}

The basic feature of the automated liquid-chromatographic analyser has been described earlier $(6,7)$. For the present method it was slightly modified. Briefly, it includes the following units (fig. 1):

the automated sample injector, the sample clean-up unit, the chemical modulator, the chromatographic and quantification unit, and a microprocessor control unit.

The sample injector consists of a sampler and a peristaltic pump from an AutoAnalyzer I (Technicon Instruments, Tarrytown, NY, USA). Samples were loaded by switching a 1 ml-loop into the line of the analyser.

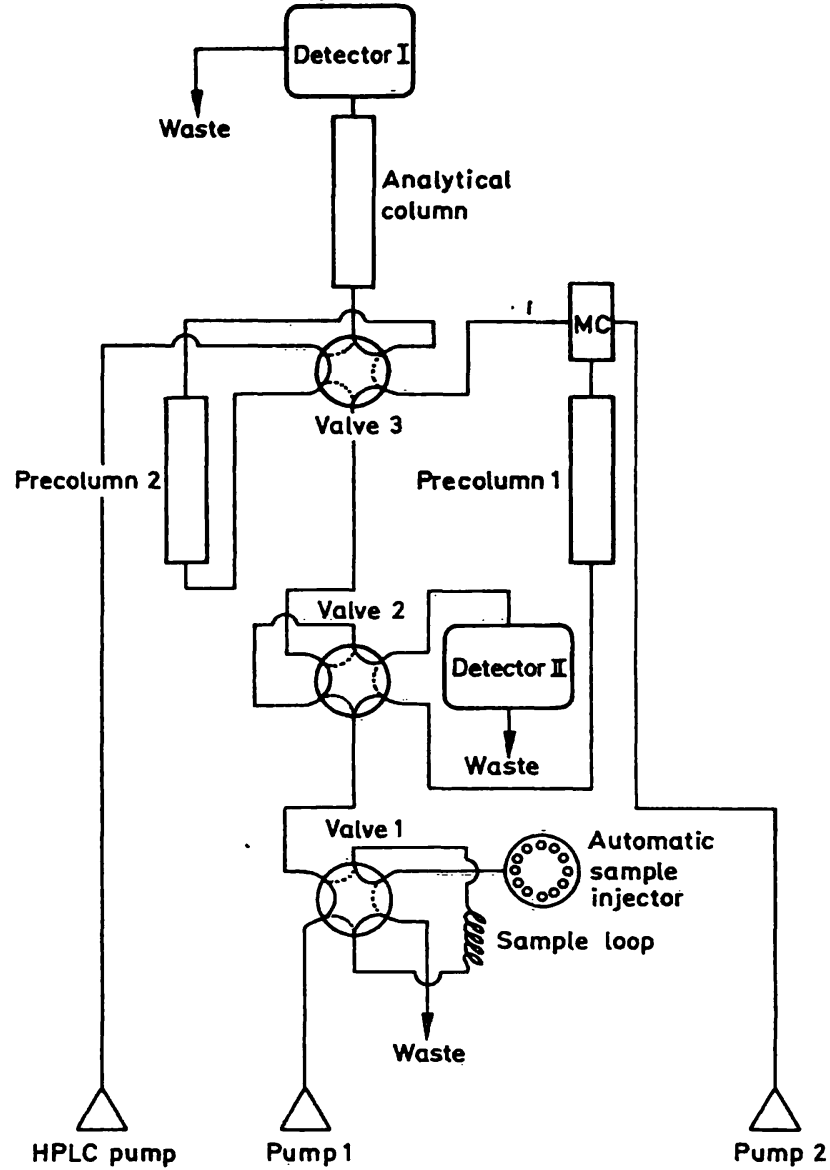

Fig. 1. Flow diagram of the automated liquid chromatographic assay of urinary oestriol-16-glucuronide. Valves 1,2 and 3 are shown in position I; the broken lines indicate position II. The pumps (P1, P2, HPLC-P), sample injector, precolumns, analytical column and the mixing chamber (MC) are described in the text.

The sample clean-up unit consists of a high pressure pump (P1) with a ternary mixing device (Model LC $=4 \mathrm{~A}$, Shimadzu, Kyoto, Japan), two motor-driven high pressure six way valves (V1, V2), an ultraviolet-detector (Det. II) set at $275 \mathrm{~nm}$, and a precolumn (C1) $(40 \times 60 \mathrm{~mm})$ packed with PRP-I particles from Dr. Knauer GmbH, Berlin, F.R.G.

The chemical modulation unit consists of a mixing chamber (MC), a double plunger pump (P2) (Dr. Knauer), a six way valve (V3) and a precolumn (C2) $(40 \times 60 \mathrm{~mm})$ packed with ODS-Hypersil from Shandon, Southern, U.K.

The quantification unit consists of a ternary high pressure pump (HPLC-P) (Model LC-4A, Shimadzu), an analytical column $(40 \times 250 \mathrm{~mm})$ prepacked with $5 \mu \mathrm{m}$ ODS-Hypersil (Shandon), a fluorimetric detector (Det. I) set at $278 \mathrm{~nm}$ for excitation and at $305 \mathrm{~nm}$ for emission, and an integrator (Model C-R3AX, Shimadzu).

All modules of the system were operated by the microprocessor control unit, implemented in the CR-3AX-integrator.

\section{Methods}

Samples

Aliquots of about $20 \mathrm{ml}$ from a single morning urine sample of pregnant women were stored and frozen until analysis. 


\section{Determination of oestriol-16-glucuronide}

Urine is diluted $1: 100$ with water, and about $1.5 \mathrm{ml}$ of the diluted urine are transferred to the sampler of the automatic analyser.

The following analytical steps were time-controlled by the electronic controller in such a manner that steps $1-4$ as well as 6 were run concomitantly with the chromatographic step 5 .

Step $11 \mathrm{ml}$ of diluted urine is transferred from the sampler into the sampling loop of the sampling unit.

Step 2 The loop is switched into the analytical line. During this time $(1 \mathrm{~min})$ valve 1 is switched into position II. Pump 1 delivers a $\mathrm{pH}$ 7-buffer (phosphoric acid/LiOH) (flow-rate $3 \mathrm{ml} / \mathrm{min}$ ) mixed with methanol $(92+8$ by vol.) for 6 minutes. All lipophilic compounds are adsorbed on column 1, and substances more polar than oestriol-16-glucuronide are eluted.

Step 3 A pH 11-buffer (tris(hydroxymethyl)methylamine/ $\mathrm{LiOH}$ ) (flow-rate $2 \mathrm{ml} / \mathrm{min}$ ) mixed with methanol (76 +24 by vol.) is delivered by pump 1 . Oestriol-16glucuronide is eluted from column 1 into the mixing chamber.

Step 4 A pH 2-buffer (phosphoric acid/LiOH) (flow-rate 0.5 $\mathrm{ml} / \mathrm{min}$ ) is delivered by pump 2 into the mixing chamber. Valve 3 is switched into position II. Oestriol-16glucuronide, in its neutral phenolic form, is focused onto the top of column 2 .

Step 5 Valve 3 is switched back into position I. Column 2 is switched into the line with the analytical column. By running a gradient from 18 to $20 \%$ acetonitrile with a $\mathrm{pH}$ 2-buffer (phosphoric acid/LiOH), the prepurified, focused fraction is chromatographed on the analytical column. The oestriol-16-glucuronide is quantified by fluorimetric detection (Det. I).

Step 6 Valve 2 is switched into position II and acetonitrile is delivered by pump 1 . Thus, all residual material, more lipophilic than oestriol-16-glucuronide is eluted from column 1 in "back-flush" -mode into the waste.

\section{Determination of total urinary oestriol}

This method, using the same instrumental settings, has been described earlier (6).

\section{Results}

Procedural variables

\section{Procedural losses}

While running a water sample spiked with $50 \mathrm{mg} / \mathrm{l}$ of oestriol-16-glucuronide and monitoring the ultraviolet absorbance during and after the clean-up procedure by detector II, no absorbance was observed, thus indicating that the oestriol-16=glucuronide was nearly quantitatively transferred to the analytical column.

\section{Stability and quality of the chromatographic system}

For 200 analyses of urine samples, run with the same instrument settings, the chromatographic resolution and peak shape were of consistent quality, as was the analytical recovery of a $21.5 \mu \mathrm{mol} / \mathrm{l}$ aqueous solution of oestriol-16-glucuronide.

There was no significant alteration of retention time $(\mathrm{CV}=0.6 \% ; \mathrm{n}=50)$.

The precolumns were stable for 500 runs, the analytical column for 1000 runs.

\section{Analytical variables}

\section{Calibration}

A standard curve by external calibration was established by spiking a urine sample from a male with different amounts of oestriol-16-glucuronide. The concentrations of oestriol-16-glucuronide ranged from 1 to $107 \mu \mathrm{mol} / 1$. Unknowns were evaluated by integral interpolation using the response factor calculated from the linear standard curve. The smallest amount of oestriol-16-glucuronide we could quantify was 430 $\mathrm{nmol} / \mathrm{l}$ (signal/noise ratio $=3$ ).

\section{Precision}

The intra- and inter-assay variability was assessed by replicate analysis of a male urine sample, spiked with a concentration of oestriol-16-glucuronide of 21.5 $\mu \mathrm{mol} / \mathrm{l}$.

Coefficients of variation were $4.4 \%(n=12)$ for intraand $7.8 \%(\mathrm{n}=9)$ for inter-assay precision.

\section{Accuracy}

The accuracy was assessed by replicate analysis of a male urine sample, spiked with four different concentrations of oestriol-16-glucuronide, ranging from 1 to $107 \mu \mathrm{mol} / \mathrm{l}$. The average recovery was $99( \pm 4) \%$.

\section{Specificity}

The effect of the intensive prepurification, which eliminates the nonspecific background of urinary chromogens, is illustrated in figure 2, comparing a urine sample of a male with a urine sample of a woman at 40 weeks of gestation (oestriol-16-glucuronide concentration is $81.74 \mu \mathrm{mol} / \mathrm{l})$.

The specificity of the present technique is mainly achieved by exploiting the phenolic and acidic nature of the oestriol-16-glucuronide molecule. Thus at the end of clean-up procedure, neutral and acidic molecules with a chromatographic behaviour similar to that of oestriol-16-glucuronide, are almost completely eliminated. 


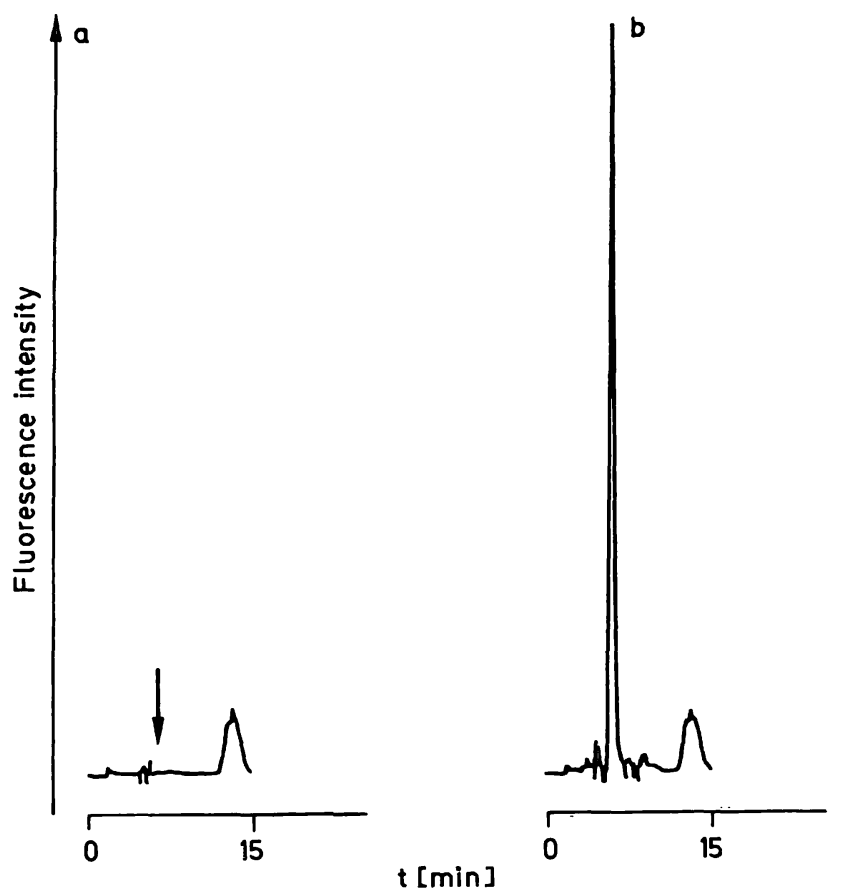

Fig. 2. Fluorimetric chromatograms of urine samples.

a) urine, from a male

b) urine from a pregnant woman at 40 weeks of gestation (oestriol-16-glucuronide concentration: 81.74 $\mu \mathrm{mol} / \mathrm{l})$.

Arrow indicates elution time of oestriol-16-glucuronide.

\section{Practicability}

In the present automated system, the only manual steps of the analysis are the sample-dilution and the transfer of the sample to the sampler; hydrolysis by acidification and heating is unnecessary. The analyser produces results in $\mu \mathrm{mol} / \mathrm{l}$. Analysis of one or a series of samples is started by a switch of the controller. Furthermore, unattended operation is feasible, if the microprocessor unit is programmed appropriately. To avoid evaporation when larger series are analysed, the sample cups are sealed with a plastic film.

The interval from sampling to the first result, including pretreatment and chromatographic phase, is about 25 minutes. When samples are run serially, the time for analysis is determined only by the chromatographic time (15 $\mathrm{min})$.

Thus, for the described assay, 96 samples may be handled during one day, if overnight operation is included.

\section{Comparison with total urinary oestriol}

Oestriol-16-glucuronide was determined in urine samples from 85 pregnant women $(7-41$ weeks of gestation) and the results were compared with those for total urinary oestriol determined by a liquid-chromatographic method (6).
The correlation of steroid concentration is depicted in figure 3. The equation of correlation was:

oestriol-16-glucuronide ( $\mu \mathrm{mol} / \mathrm{l})$

$=1.64 \mu \mathrm{mol} / 1+(0.73 \times$ oestriol $(\mu \mathrm{mol} / 1))$;

$\mathrm{r}=0.957$.



Fig. 3. Comparison of oestriol-16-glucuronide, measured by fluorimetric detection (y), with total oestriol, measured by uv-detection (x), in the urine of pregnant women. $y=1.64+0.73 x$ $r=0.957$

\section{Data in pregnancy urines}

Figure 4 depicts the results of excretion rates of urinary oestriol-16-glucuronide in specimens from ambulant women, who had normal pregnancies. Excretion rates are expressed relative to the creatinine excretion rate in mmol oestriol-16-glucuronide (E-3$16 \mathrm{G})$ per mol creatinine. Data are related to the stage of gestation.

The corresponding reference ranges of relative excretion rates are listed in table 1.

Tab. 1. Relative urinary excretion rates of oestriol-16-glucuronide in normal late pregnancy.

Results expressed as lower limit, median and upper limit of measured data.

\begin{tabular}{llllll}
\hline $\begin{array}{l}\text { Weeks of } \\
\text { gestation }\end{array}$ & \multicolumn{2}{l}{ Oestriol-16-glucuronide (mmol) } & & n \\
\cline { 2 - 4 } & \multicolumn{2}{c}{ Creatinine (mol) } & & \\
\cline { 2 - 4 } & Lower & Median & Upper & & \\
\hline 31 & 1.66 & 2.20 & 2.76 & \\
32 & 1.80 & 3.37 & 4.95 & 3 \\
33 & 2.74 & 2.84 & 3.02 & 2 \\
34 & 2.35 & 3.85 & 5.49 & 3 \\
35 & 2.89 & 5.38 & 7.50 & 3 \\
36 & 2.18 & 5.26 & 6.64 & 4 \\
37 & 2.89 & 5.61 & 8.40 & 7 \\
18 & 2.89 & 4.86 & 8.29 & 7 \\
39 & 2.91 & 5.94 & 9.12 & 8 \\
40 & 4.37 & 7.49 & 12.99 & & 15 \\
\hline
\end{tabular}




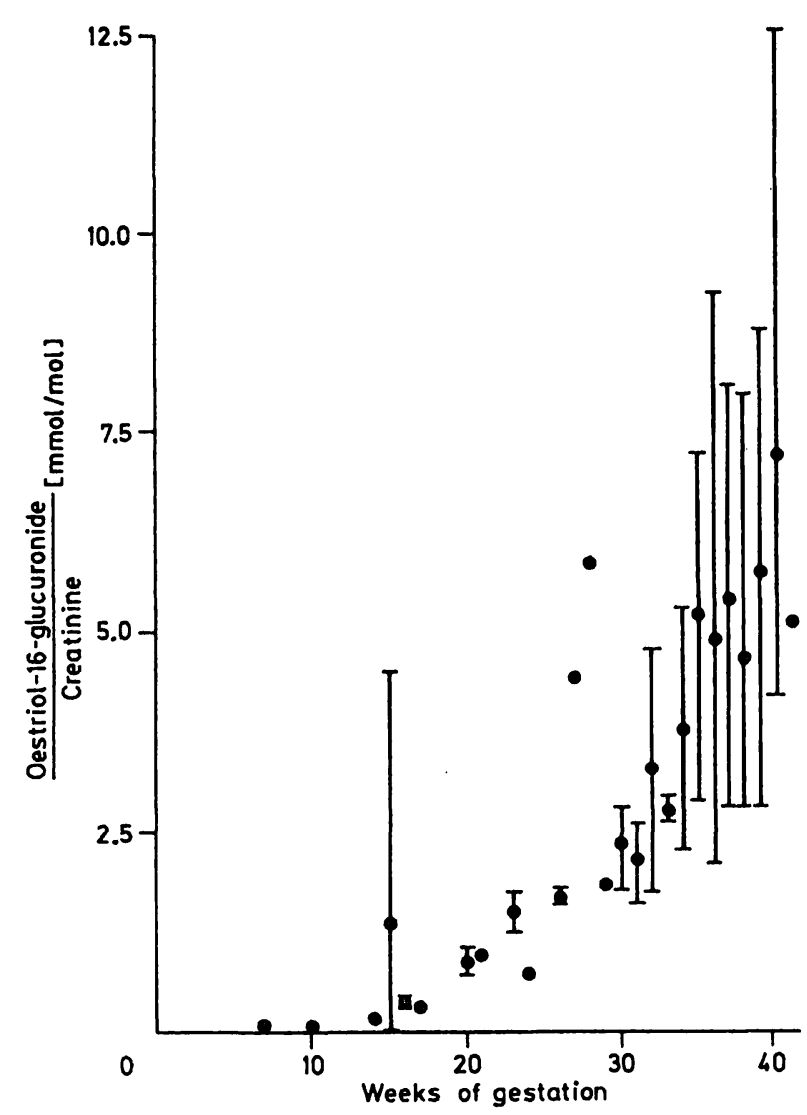

Fig. 4. Excretion rates of urinary oestriol-16-glucuronide relative to creatinine $(y)$ in relation to stage of gestation (x).

Excretion expressed as lower limit, median and upper limit.

\section{Discussion}

The outstanding feature of this method is the high efficiency of the sample clean-up combined with the specific estimation by fluorimetric detection.
Manual operation is reduced to dilution of the samples. Further advantages of this method are: the analyte is kept in solution throughout the assay, thus avoiding potential loss or decomposition; because of the good precision and the negligible procedural losses, only a single external calibration is necessary for the evaluation of results; the regeneration of precolumns and the use of inexpensive solvents renders the method relatively economical.

In addition, using the same instrumental settings and the same solvents, other analytes $(6-10)$ can also be assayed simply by selectively activating the corresponding programs.

The good correlation between the excretion rates of oestriol-16-glucuronide and the total oestriol demonstrates that the estimation of urinary oestriol-16glucuronide provides a diagnostic approach for monitoring the function of fetal/maternal unit, which is equivalent to that of total urinary oestriol. Since the present method for urinary oestriol-16-glucuronide estimation does not involve hydrolysis, it is suitable for prophylactic examinations during pregnancy, and particularily for the acute biochemical monitoring of fetal well-being under emergency conditions.

\section{Acknowledgement}

We gratefully acknowledge the provision of urine samples by Prof. Dr. W. Busch, Dept. of Gynaecology \& Obstetrics, Klinikum Charlottenburg, Freie Universität Berlin.

\section{References}

1. Gurpide, E., Giebenhain, M. E., Tseng, L. \& Kelly, W. G. (1971) Am. J. Obstet. Gynecol. 109, 897-906.

2. Kallner, A. \& Lantto, O. (1977) Clin. Chim. Acta 79, 325330.

3. Andreolini, F., Di Corcia, A., Lagana, A., Samperi, R. \& Raponi, G. (1983) Clin. Chem. 29, 2076-2078.

4. Andreolini, F., Borra, C., Caccamo, F., Di Corcia, A., Nicoletti, I., Samperi, R. \& Improta, F. (1985) Clin. Chem. 31, 1698-1702.

5. Andreolini, F., Borra, C., Di Corcia, A., Samperi, R. \& 'Raponi, G. (1985) Clin. Chem. 31, 124-126.

6. Schöneshöfer, M., Dhar, T. K. \& Ionides, D. (1986) Clin. Chem. 32, 1948-1950.

7. Schöneshöfer, M., Kage, A., Eisenschmid, B., Heilmann, P., Dhar, T. K. \& Weber, B. (1986) J. Chromatogr. 380, $267-274$.

8. Schöneshöfer, M., Kage, A. \& Weber, B. (1983) Clin. Chem. 29, 1376-1371.

9. Schöneshöfer, M., Kage, A., Weber, B., Lenz, I. \& Köttgen, E. (1985) Clin. Chem. 31, 564-568.

10. Eisenschmid, B., Heilmann, P., Oelkers, W., Rejaibi, R. \& Schöneshöfer, M. (1987) J. Clin. Chem. Clin. Biochem. 25, $345-349$.

Prof. Dr. med. Dr. rer. nat. M. Schöneshöfer Abteilung für Laboratoriumsmedizin Städtisches Krankenhaus Berlin-Spandau Lynarstraße 12

D-1.000 Berlin 20 
